\title{
Avaliação "in vitro" da influência do cimento adesivo Panavia EX na infiltração marginal de restaurações de amálgama de prata
}

\author{
Susana Maria Werner Samuel* \\ Luiz Antônio Ruhnke** \\ Simonides Consani**
}

\begin{abstract}
RESUMO
O objetivo deste trabalho foi avaliar "in vitro" o efeito

do cimento adesivo Panavia EX na microinfiltraçāo de restauraçōes de amálgama.

Trinta dentes humanos com cavidades classe $\mathrm{V}$ foram divididos em 3 grupos e restaurados da seguinte forma: no grupo $\mathrm{A}$ todas as cavidades foram restauradas apenas com amálgama; no grupo B uma camada de Panavia EX foi aplicada às paredes cavitárias antes da restauraçāo e no grupo $\mathrm{C}$, o esmalte do contorno da cavidade foi condicionado com ácido, as paredes da cavidade protegidas com Panavia EX e entäo restauradas com amálgama.

Os dentes foram imersos numa solução de azul de metileno e os resultados indicaram que: a) todas as restauraçōes de amálgama sem Panavia EX mostraram infiltração severa e moderada; b) as restauraçōes forradas com Panavia EX tiveram reduzida infiltração quando comparadas com o controle (Grupo A); e,

c) não houve influência do condicionamento ácido quanto à infiltração marginal.
\end{abstract}

\section{SUMMARY}

The purpose of this study was to evaluate, "in vitro" the effect of the adhesive resin cement lining (Panavia EX) in reducing microleakage of amalgam restorations with or without a enamel acid etching treatment.

Thirty human teeth with class $V$ cavity preparations were divided in three groups and restored as folows: group $A$ - the teeth were restored with amalgam only; group B - one layer of Panavia EX was applied to the cavities before the restoration; and group $\mathrm{C}$ - the enamel of the cavity margins were acid etched, the cavity walls protected with

Panavia EX and then restored.

The teeth were then immersed in a solution of methylene blue. The analysis of the results indicated that: a) all the amalgam restorations without Panavia EX showed important microleakage (70\% severe and $30 \%$ moderate); b) the restorations protected with Panavia EX showed reduced microleakage when compared with the control (group A);

c) the acid etching did not influence the microleakage results.

\section{UNITERMOS}

Amálgama, Microinfiltração, cimento adesivo.

\section{Introdução}

Para que uma restauração dentária obtenha sucesso clínico é necessário que, além de manter a forma e as dimensões, adapte-se perfeitamente às paredes cavitárias impedindo a microinfiltração.

Mesmo com o desenvolvimento de novos materiais restauradores diretos, o amálgama satisfaz várias condiçōes de um restaurador ideal $\mathrm{e}$ permanece como material de escoIha para muitas aplicaçōes clínicas (01). Quanto às suas propriedades físicas, as ligas para amálgama utilizadas atualmente satisfazem plenamente as exigências da especificação $n^{\circ} 1$ da A.D.A. Com relação às propriedades químicas, por ser uma liga metálica, o amálgama não oferece problemas em termos de solubilidade e absorção d'água como ou- tros materiais restauradores, porém, não apresenta a propriedade de adesão aos componentes orgânicos ou inorgânicos do esmalte ou dentina (02).

As restauraçōes recentes de amál-

* Professora de Materiais Dentários da Faculdade de Odontologia da UFRGS.

** Professores de Materiais Dentários da Faculdade de Odontologia de Piracicaba - UNICAMP. 
gama que a olho nu parecem perfeitamente adaptadas, quando observadas sob microscopia eletrônica mostraram uma fenda na interface dente/restauraçăo (03), e a substituiçăo de restauração devido à reincidência de cárie em função da microinfiltração tem siddo um problema contínuo para a Odontologia Restauradora (04). Por isso, o material restaurador ideal deveria unir-se quimicamente à estrutura dental (05) por si só ou através de um agente de forramento adesivo e insolúvel, para prevenir a microinfiltraçăo (04).

Em 1984 surgiu um cimento resinoso adesivo (Panavia EX), que tem afinidade por íons metálicos e teoricamente pode aderir-se aos metais e ao dente (06). Este cimento foi inicialmente indicado para cimentação de próteses tipo "Maryland Bridges", mas em 1987, Shimizu et al (07) testaram este sistema adesivo com amálgama em restauraçōes de dentes com grande destruição coronária e relataram sucesso clínico. Mais tarde também foi observada a reduçăo da reincidência de cárie (08), além do aumento da resistência à tração (09) e ao deslocamento (10) nas restauraçōes de amálgama de prata forradas com este cimento.

Por todos esses motivos e considerando que a microinfiltração é um problema, propusemo-nos avaliar a eficácia do cimento adesivo Panavia EX, na redução da microinfiltração em restauraçōes de amálgama de prata.

\section{Materiais e Métodos}

Para a realização deste trabalho foram usados os seguintes materiais: uma liga de amálgama com alto teor em cobre, Dispersalloy (Johnson \& Johnson Dental Products, East Windsor, N.J.), um mercúrio bidestilado, Mercúrio Puro (Ourodent, Brasil) e um cimento resinoso adesivo, Panavia EX (Kuraray Co., Kurashiki, Japan).

Foram utilizados trinta dentes humanos dos grupos pré-molares e caninos, recém-extraídos e submetidos a uma profilaxia com pasta de pedra-pomes e água. Apenas os dentes que năo apresentavam ra- chaduras, foram selecionados e armazenados em água à temperatura ambiente até serem submetidos ao preparo cavitário.

Cavidades classe $V$ foram preparadas no terço médio da face vestibular dos dentes, com pontas diamantadas cilíndricas no 1093 (K.G. Sorensen), montadas em uma turbina pneumática (Dabi Atlante), com velocidade de 300.000 r.p.m. e refrigerada a ar e água. Para os preparos cavitários, a caneta de alta rotação foi acoplada ao corpo de um microscópio óptico e o dente fixado a uma calha metálica parafusada à platina deste dispositivo de maneira que as dimensōes da cavidade pudessem ser controladas por meio da movimentação do dente nos sentidos ântero-posterior, latero-lateral e vertical, estabelecidas pelos parafusos micrométricos.

Todas as cavidades confeccionadas apresentavam as seguintes dimensōes: $2 \mathrm{~mm}$ em profundidade, $3 \mathrm{~mm}$ no sentido mésio-distal e $1,5 \mathrm{~mm}$ no sentido ocluso-gengival.

Os materiais foram preparados e utilizados de acordo com as instruções do fabricante e os dentes divididos em três grupos de dez elementos:

Grupo A (controle): as dez cavidades deste grupo receberam somente restauraçōes de amálgama de prata. A relação liga/mercúrio utilizada foi $1: 1$, em peso de forma que $430 \mathrm{mg}$ de liga e $430 \mathrm{mg}$ de mercúrio foram colocadas numa cápsula rosqueável, sem pistilo, adaptada ao amalgamador mecânico (Dentomat-Degussa), calibrado para 15 segundos de trituração. O amálgama foi condensado na cavidade com condensador mecânico (Dabi Atlante), com ponta ativa de $1 \mathrm{~mm}$ de diâmetro. Os excessos de material restaurador foram removidos com uma espátula tipo Holemback (3S) e os dentes armazenados por 24 horas a $37^{\circ} \mathrm{C}$ e $100 \%$ de umidade relativa do ar.

Grupo B (experimental): antes da condensação do amálgama, as paredes internas das cavidades deste grupo foram protegidas com uma camada de cimento adesivo Panavia
EX. O cimento foi manipulado com espátula de teflon num bloco do papel impermeável na proporçăo de uma medida de pó para uma gota de líquido, por 60 segundos e imediatamente pincelado nas paredes da cavidade. A condensaçāo do amálgama, nas mesmas condiçōes descritas para o grupo $A$, foi feita sobre o cimento resinoso ainda plástico. Para impedir que o oxigênio presente no ar inibisse a polimerizaçāo deste material, o contorno da restauraçāo foi protegido com Oxyguard (gel de álcool polivinílico), por seis minutos. A seguir, o Oxyguard foi removido e os dentes armazenados por 24 horas a $37^{\circ} \mathrm{C}$ e $100 \%$ de umidade relativa do ar.

Grupo C (experimental): as cavidades deste grupo tiveram o esmalte cavo-superficial submetido a um condicionamento ácido antes da proteção com o cimento adesivo Panavia EX. A sequência foi a seguinte: 1) condicionamento de $1 \mathrm{~mm}$ do esmalte cavo-superficial com ácido fosfórico (37\%), por 30 segundos; 2) lavagem com água, por 30 segundos e secagem, com jatos de ar, por 20 segundos; 3) aplicação do cimento resinoso com pincel nas paredes internas e ângulo cavo-superficial; 4) condensação do amálgama; 5) proteção com Oxyguard; 6) remoção do Oxyguard após 6 minutos e armazenagem por 24 horas a $37^{\circ} \mathrm{C}$ e $100 \%$ de umidade relativa do ar.

Vinte e quatro horas após restaurados, cada grupo de dentes foi submetido a 100 ciclos térmicos, com banhos de água a $5^{\circ} \mathrm{C}$ onde permaneciam 60 segundos intercalados por um banho a $37^{\circ} \mathrm{C}$, por 30 segundos, para estabilizaçāo da temperatura antes de cada imersão fria ou quente.

Após o ciclo térmico, os dentes foram secos e isolados com esmalte para unha e cerca rosa $n^{\circ} 7$ até uma distância de $2 \mathrm{~mm}$ da restauração. A seguir, foram imersos numa soluçăo aquosa de azul de metileno a $0,5 \%$ onde permaneceram a $37^{\circ} \mathrm{C}$ durante 72 horas. Decorrido o tempo de imersão no corante, os dentes foram lavados e as camadas isolantes de esmalte e cera, removidas. Com o 
A tabela 1 apresenta os níveis de infiltração observados nas dez restauraçőes de cada grupo.

A partir dos dados da tabela 1, foi feita uma análise estatística a fim de avaliar se houve diferença significativa entre os níveis de infiltração de cada grupo. Foi utilizado o teste não-paramétrico de Kruskal-Wallis, onde o valor calculado de $\mathrm{H} 1$ foi 18,9312 e o valor de distribuição de Qui-quadrado ao nível de significância de $5 \%$, com 2 graus de liberdade,

foi 5,99. O teste complementar de Comparação Múltipla das Médias mostrou que o grupo A apresentou níveis de infiltração estatisticamente superiores aos grupos $\mathrm{B}$ e $\mathrm{C}$, sendo que esses últimos não diferiram estatisticamente entre si (d.m.s. = 9,2257).

O gráfico 1 ilustra a porcentagem de distribuição dos níveis de infiltração de cada grupo, sendo que no grupo A, $30 \%$ das restaurações mostraram nível 2 e $70 \%$, nível 3; no grupo B, $40 \%$ mostraram nível zero, $40 \%$, nível 1 e $20 \%$ nível 2; e, no grupo C, $60 \%$ nível 1 e $40 \%$ nível 2 .

\section{Discussão}

De acordo com os resultados obtidos neste trabalho, observa-se que $100 \%$ das restaurações de amálgama, sem qualquer tipo de forramento (grupo A), apresentaram infiltração severa ou moderada, indicando que em todas as restauraçōes houve penetração do corante nos túbulos dentinários, sendo que, na maioria $(70 \%)$, o corante atingiu a câmara pulpar. Esses dados comprovam que as restaurações de amálgama de prata recém-confeccionadas permitem um fluxo de líquidos na interface dente/restauração que pode alcançar o órgão pulpar. Going et al (11) também verificaram infiltraçăo marginal ao nível de dentina nas restaurações recentes de amálgama. Da mesma forma Swartz e Phillips (12), Going e Sawuinski (13), Boyer e Torney (14), Hembree e Andrews (15), mostraram que as restauraçōes recentes de amálgama apresentam infiltração marginal nos períodos iniciais. McCurdy Junior et al (16) também afirmaram que o selamento marginal das restauraçōes de amál-
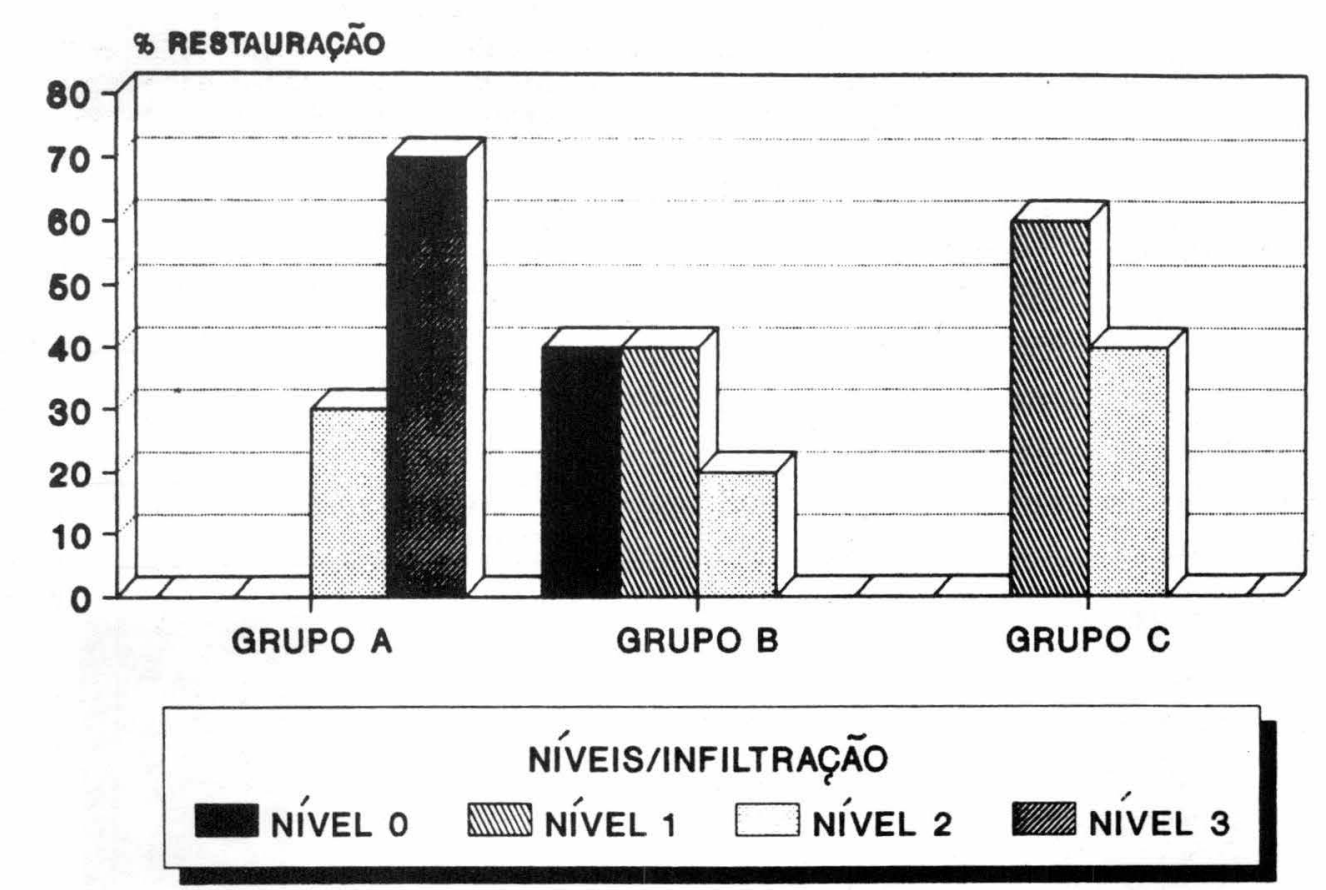

Gráfico 1 - Distribuição dos níveis de infiltração das restaurações de cada grupo (\%) gama de prata é muito pobre após 24 horas, tanto "in vivo" como "in vitro". Baumgartner et al (17) por sua vez, observaram que, independente da idade das restauraçōes de amálgama, $80 \%$ delas mostraram infiltração marginal. Portanto, os autores sāo unânimes em afirmar que as restauraçōes recentes de amálgama sem forramento apresentam infiltraçăo marginal confirmando os resultados do grupo A (controle), obtidos neste trabalho.

Andrews e Hembree (18) mostraram que a microinfiltraçāo nas ligas de alto teor de cobre diminui mais lentamente devido, provavelmente, à sua menor corrosăo, concordando com Gottlieb et al (19), que acreditam que as ligas com alto teor de cobre permitem maior infiltraçāo. Já Vasudev et al (20) afirmaram que apesar das ligas convencionais serem mais favoráveis ao selamento das restauraçōes, sempre ocorre microinfiltração nos três primeiros meses, independente do tipo de liga utilizada, o que também justifica a necessidade da utilização de um agente de forramento insolúvel e adesivo às estruturas dentárias.

Os resultados alcançados com os grupos experimentais deste trabalho mostraram que houve redução da microinfiltração nas restauraçōes de amálgama sempre que o cimento resinoso adesivo Panavia EX foi utilizado. A análise estatística dos resultados mostrou que os grupos B (forrado com Panavia EX) e $C$ (condicionado com ácido e forrado com $\mathrm{Pa}$ navia) não são estatisticamente diferentes entre si, mostrando reduzida infiltração marginal quando comparados com o grupo $A$ (controle).

Com relaçăo à variável condicionamento ácido do esmalte para reduzir a microinfiltração, encontramos em Buonocore (21) seu primeiro defensor, enfatizando que este procedimento promove "adesão mecânica" dos materiais resinosos ao esmalte, diminuindo a microinfiltração. O trabalho de Gwinnet e Buonocore (22) confirma tal teoria e Staninec e Holt (09) afirmaram que sem ataque ácido não se obtêm adesões consistentes.

Talvez por isso, exista um aspecto sempre presente nos trabalhos que 
testaram o cimento Panavia EX na nova técnica adesiva, ou seja, a sua execução sobre esmalte submetido ao ataque ácido para aumentar a retenção mecânica. Omura et al (06), que apresentaram o novo cimento e o próprio fabricante afirmaram que o material é adesivo à estrutura dental através de um éster fosfatado que tem uma forte interação com os íons da superfície dentária. No entanto, não foi encontrado na revisão bibliográfica nenhum trabalho que testasse a adesão deste cimento ao esmalte não condicionado, para verificar se ocorre alguma união além daquela favorecida pelo ataque ácido.

Porém, neste trabalho pode-se observar, pelos dados obtidos e confirmados pela análise estatística, que não houve influência do condicionamento ácido do esmalte quanto à infiltração marginal. Esses dados levam a crer que realmente existe álgum tipo de adesão entre o cimento Panavia EX e a estrutura dental sem condicionamento ácido, uma vez que, mesmo com menor embricamento mecânico, houve também redução de microinfiltração no grupo B, não submetido ao condicionamento ácido. A presença de partículas de carga na resina aumentando a viscosidade talvez tenha reduzido o escoamento do Panavia EX para o interior da estrutura do esmalte condicionado pelo ácido, o que poderia justificar o fato de năo ter havido diferença significativa entre os grupos experimentais $\mathrm{A}$ e $\mathrm{B}$, quanto aos níveis de penetração do corante.

Os resultados mostram que o cimento resinoso adesivo Panavia EX realmente reduz a infiltração marginal e que essa redução ocorre independente de haver ou não condicionamento ácido do esmalte. Se a etapa do condicionamento ácido não interfere significativamente no resultado final, parece lícito deduzir que se trata de um passo perfeitamente dispensável na nova técnica de restauraçāo de amálgama. Podendo suprimir uma etapa no processo da restauração haverá economia de tempo e material, além de menor agressão à estrutura dental.

Assim sendo, parece que o amálgama, considerado o material restau- rador mais antigo, pode melhorar ainda mais o seu desempenho, combinando as suas qualidades com as vantagens da adesão.

\section{Conclusão}

Todas as restaurações de amálgama de prata realizadas sem forramento cavitário apresentaram infiltração marginal $(70 \%$ severa e $30 \%$ moderada).

As restaurações de amálgama de prata forradas com o cimento resinoso adesivo Panavia EX tiveram reduzida infiltração marginal e não houve influência do condicionamento ácido do esmalte sobre a infiltração marginal nas restauraçōes forradas com esse cimento.

\section{REFERÊNCIAS BIBLIOGRÁFICAS}

01. PHILLIPS, R.W.; JENDRESEN, M.D.; KLO OSTER, J.; McNEIL, C.; PRESTON, J.D.; SCHALLHORN, R.G. Report of the committee on scientific investigation of the american academy of restorative dentistry. J. Prosthet Dent., 1989, 62:70-101.

02. BROWN, D. Dental amalgam. Br. Dent. J., 1988, 164:253-6.

03. MERTZ-FAIRHURST, E.J.; NEWCOMER, A.P. Interface gap at amalgam margins. Dent. Mater, 1988, 4:122-8.

04. STANINEC, M.; JOW, R.W.; KIRCOS, L.T.; HOOVER, C.I. "In vitro" caries induction at the tooth amalgam interface. Dent. Mater, 1988, 4:72-6.

05. PHILLIPS, R.W.; GILMORE, H.W.; SWARTZ, M.L.; SCHENKEL, S.I. Adaptation of restorations "in vivo" as assessed by $\mathrm{Ca}$ 45. J. Am. Dent. Ass., 1961, 62:23-34.

06. OMURA, I.; YAMAUCHI, J.; HARADA, I.; WADA, T. Adhesive and mechanical properties of a new dental adhesive. J. Dent. Res., 1984, 63:233.

07. SHIMIZU, A.; UI, T.; KAWAKAMI, M.; TSUCHITANI, Y. Amalgam restoration using an adhesive resin cement as a cavity liner. J. Osaka Univ. Dent. Sch., 1987, 27:147-55.

08. TORII, Y.; STANINEC, M.; KAWAKAMI, M.; IMAZATO, S.; TORII, M.; TSUCHITANI, Y.; Inhibition of caries around amalgam restoration by amalgam bonding. J. Dent. Res., 1988, 67:308.

09. STANINEC, M.; HOLT, M. Bonding of amalgam to tooth structure: tensile and microleakage tests. J. Prosthet Dent., 1988; 59:397-402.

10. STANINEC, M. Retention of amalgam restorations: undercuts versus bonding. Quintess. Int., 1989, 20:347-51.

11. GOING, R.E.; MASSLER, M.; DUTE, H.L. Marginal penetrations of dental restorations as studied by cristal violet dye and I (131). J. Am. Dent. Ass., 1960, $61: 285-300$.
12. SWARTZ, M.L.; PHILLIPS, R.W. In vitro studies on the marginal leakage of restorative materials. J. Am. Dent. Ass., 1961, 62:141-51

13. GOING, R.E.; SAWINSKI, V.J. Microleakage of a new restorative material. J. Am. Dent. Ass., 1966, 73:107-15.

14. BOYER, D.B.; TORNEY, D.L. Microleakage of amalgam restorations with high-copper content. J. Am. Dent. Ass., 1979, 99:199-202

15. HEMBREE, J.H.; ANDREWS, J.T. Microleakage of corrosion resistant amalgam alloys. J. Dent. Res., 1979, 58:397.

16. McCURDY JUNIOR, C.R.; SWARTZ, M.L.; PHILLIPS, R.W.; RHODES, B.F. A comparison of "in vivo" and "in vitro" microleakage of dental restorations. J. Am. Dent. Ass., 1974, 88:592-602.

17. BAUMGARTNER, W.J.; BUSTARD, R.E. FEIERABEND, R.F. Marginal leakage of amalgam restorations. J. Prosthet Dent. 1963, 13:346-53.

18. ANDREWS, J.T.; HEMBREE JUNIOR, J.H. Marginal leakage of amalgam alloys with high content of copper: a laboratory study. Operative Dent., 1980, 5:7-10.

19. GOTTLIEB, E.W.; RETIEF, D.H.; BRADLEY, E.L. Microleakage of conventional and high-copper amalgam restorations. J. Prosthet Dent., 1985, 53:353-61.

20. VASUDEV, U.B.; MOHAMED, H.; SHEN, C. Real time quantitation of microleakage around dental restorations: dental amalgam. J. Dent. Rest., 1981, 60:521.

21. BUONOCORE, M.G. A simple method of increasing adhesion of acrylic filling materials to enamel surfaces. J. Dent. Res., 1955, 34:849-53.

22. GWINNET, A.J.; BUONOCORE, M.G Adhesives and caries prevention: a preliminary report. Br. Dent. J., 1965, 119:77-81. 